Filol. linguíst. port., São Paulo, 15(1), p. 47-66, Jan./Jun. 2013.

DOI: 10.11606/issn.2176-9419.v15i1p47-66.

\title{
O conector por causa que: gramaticalização e análise de propriedades gramaticais e semântico-discursivas ${ }^{1}$
}

The connective por causa que: grammaticalization and analysis

of grammatical and semantic-discursive properties

\author{
Fabrício da Silva Amorim \\ Universidade Estadual Paulista, Brasil \\ letrasf@hotmail.com
}

Resumo: O objetivo deste artigo é caracterizar o conector por causa que, a partir de propostas teórico-metodológicas assentadas no paradigma funcional da Gramaticalização (Hopper; Traugott, 1993). A princípio, são apresentadas hipóteses sobre a sua emergência, seguidas de uma análise que atesta o seu caráter conjuncional (Kortmann, 1997). Além disso, investigam-se os seus padrões de uso no português falado, sob um enfoque semântico-cognitivo (Sweetser, 1991; Traugott; König, 1991). As análises subsequentes tomam como ponto de partida não o por causa que em si, mas todo o complexo clausal em que essa locução conjuntiva se insere - segmento causal e segmento efeito -, com o intuito de apresentar uma descrição, sobretudo discursiva, dessas construções. Grande parte dos resultados evidencia várias convergências entre as construções com por causa que e aquelas com o conector porque, considerado o conector causal prototípico.

Palavras-chave: Gramaticalização; relação de causalidade; conector interclausal.

\footnotetext{
${ }^{1}$ Este artigo é parte da Dissertação de Mestrado intitulada "Construções causais com por causa que: um caso de gramaticalização", defendida em fevereiro de 2012 , no Programa de Pós-Graduação em Língua e Cultura da Universidade Federal da Bahia, tendo contado com a orientação da Profa. Dra. Sônia Bastos Borba Costa - que, é claro, está isenta de ser responsável por quaisquer falhas que persistirem neste texto - e o apoio financeiro da CAPES.
} 


\begin{abstract}
This article aims to characterize the Portuguese locution "por causa que"("because that"), from theoreticalmethodological proposals based on the functional paradigm of Grammaticalization. Firstly, hypotheses on "por causa que"appearance and an analysis of its status of conjunction are presented. Furthermore, the usage patterns of "por causa que"in spoken Portuguese are investigated using a semanticcognitive approach (SWEETSER, 1991; TRAUGOTT; KÖNIG, 1991). The following analyses take into consideration not only the "por causa que"clause, but the whole clausal complex in which the conjunctive phrase is inserted - causal segment and effect segment -, aiming at presenting a specially discursive description of these constructions. Most of the results show many convergences between the constructions with "por causa que"and "porque"(because), which is considered to be the prototypical causal connector.
\end{abstract}

Keywords: Grammaticalization; relation of causality; interclausal connector.

\title{
1 Introdução
}

A revista Veja, em edição de 11 de agosto de 2010, publicou artigo criticando o desempenho linguístico dos candidatos à Presidência da República no primeiro debate exibido na TV, naquele ano. Sob um enfoque carregado de preconceito linguístico, tal artigo apresentou uma seção contendo os "10 erros de português que acabam com qualquer entrevista de emprego". Um desses erros refere-se ao uso do conector causal ${ }^{2}$ por causa que: "por causa que' é mais do que errado - nem sequer existe" (VEJA, 2010, p. 99 - grifos acrescidos).

O conector causal por causa que $e^{3}$ "inexistente" para a revista Veja - constitui o objeto de estudo deste artigo. Mais do que atestar a sua

\footnotetext{
${ }^{2}$ Ao longo deste texto, em referência ao por causa que, utilizam-se, intercambiavelmente, os termos locução (conjuntiva), conector (causal/interclausal) e item gramatical.

${ }^{3}$ Esse conector representa a forma prototípica entre suas variantes. Também foram consideradas, nesta análise, as formas "por causa/causo (de) que", "causa/causo/caus' (de) que".
} 
"existência", o presente trabalho descreve-o a partir de uma análise gramatical e semântico-pragmática, considerando ser esse um item em processo de gramaticalização. Assim, à luz de propostas teórico-metodológicas assentadas no paradigma funcional da Gramaticalização (Hopper; Traugott, 1993; Kortmann, 1997; Sweetser, 1991; Traugott; König, 1991), pretende-se investigar o desenvolvimento e usos da locução por causa que como perífrase conjuntiva que relaciona uma cláusula causal a uma cláusula efeito.

Em Paiva (2001) e Paiva e Braga (2006), verificou-se que a locução em análise, em muitos contextos, apresenta semelhanças sintáticas e semânticodiscursivas com o conector porque, considerado a conjunção causal prototípica. Nesses mesmos trabalhos, aponta-se como forma fonte do conector por causa que a locução prepositiva por causa de, mormente utilizada como conector intraclausal. Entretanto, os referidos trabalhos dispuseram de uma quantidade irrisória de ocorrências de por causa que (apenas 26), o que inviabilizou às autoras a apresentação de resultados mais acurados. No presente trabalho, portanto, com base numa amostra maior de dados, vê-se a possibilidade de apresentar resultados que contribuam para a elucidação do processo de emergência e para compreensão dos usos, na atualidade, do item gramatical em questão.

Os dados foram obtidos a partir dos seguintes corpora": "Coleção de Amostras do Português Falado no Semi-Árido Baiano", organizada na Universidade Estadual de Feira de Santana (BA); "Projeto Vertentes" (1 ${ }^{\mathrm{a}}$ fase), desenvolvido na Universidade Federal da Bahia e "Projeto Mineirês", desenvolvido na Universidade Federal de Minas Gerais. Os três corpora fornecem amostras do português brasileiro falado que se localizam na transição entre os séculos XX e XXI, como é o caso dos dois primeiros, e no início deste século (2006-2008), conforme se observa no "Projeto Mineirês". Esse recorte temporal representa, portanto, a sincronia sobre a qual o presente trabalho se debruça.

\footnotetext{
${ }^{4}$ Vale ressaltar que, na reprodução dos exemplos, manteve-se a transcrição grafemática original das entrevistas que compõem esses corpora.
} 


\section{A gramaticalização do conector por causa que}

A hipótese que norteou este trabalho prevê que, via gramaticalização (Hopper; Traugott, 1993), o conector interclausal por causa que originou-se do conector por causa de, prototipicamente intraclausal. Ainda que esta seja uma investigação sincrônica, foi necessária uma busca preliminar, com o objetivo de encontrar possíveis ocorrências de por causa que em textos representativos de períodos anteriores do português, a fim de legitimar a hipótese de que o processo de gramaticalização dessa locução é recente. Além disso, tal busca se fez necessária para aventar hipóteses acerca da inserção do subordinador que à locução por causa de, processo que resultou na constituição do conector por causa (de) que.

Como não se intentou proceder a uma investigação diacrônica, apenas uma pequena amostra foi analisada ${ }^{5}$. Nenhum dos textos consultados - datados do século XIV ao XVIII - apresentaram ocorrências do conector por causa que. Entretanto, em uma das Cartas de Cavaleiro de Oliveira (século XVIII), foi possível detectar uma ocorrência que representa um contexto suscetível à reanálise, processo aqui apresentado como hipótese possível para a formação da locução por causa que, como se vê a seguir:

(1) Disse-me que a tinha visto e, lisonjeando-me novamente a esperança, nomeei-vos também, e respondeu que vos não conhecia, dando-me por causa que só uma vez estivera na Ópera... (grifo acrescido).

Pode-se inferir, a partir da análise de (1), que o item que presente na construção grifada assume valor morfossintático de pronome relativo. Assim, torna-se possível levar em consideração a hipótese de que esse item, por reanálise, teria perdido o seu caráter de pronome, passando a ser lido como parte integrante da expressão por causa (de). De acordo com essa hipótese, a seguinte mudança ter-se-ia implementado:

\section{[por causa $($ de) $]+$ [que + oração finita] $>$ [por causa $($ de) que] + [oração finita]}

Outra explicação possível para a constituição morfossintática do conector em análise baseia-se em um mecanismo bastante presente em processos de gramaticalização de conjunções, a saber, a analogia (Cf. Barreto, 1999). Nesse

\footnotetext{
${ }^{5}$ A amostra foi constituída pelos seguintes textos: Crônica Geral de Espanha (Século XIV); Chronica de El Rey D. Dinis IV de Portugal (Século XIV); Chronica del-Rei D. Afonso Henriques (Século XV); Crônica dos Reis de Bisnaga (Século XVI); Cartas - Cavaleiro de Oliveira (Século XVIII).
} 
caso, a hipótese seria a de que, por analogia, o elemento que passou a integrar a locução por causa de, haja vista o grande número de perífrases conjuncionais de base que, muitas de largo uso no discurso oral: "assim que", "antes que", "no momento (em) que", "(n)a hora que", "por conta que" etc.

Apenas uma investigação diacrônica mais extensiva poderá ratificar uma das hipóteses assinaladas acima. O que se pode assegurar, por ora, é que, no português brasileiro atual, tendo continuado o processo de gramaticalização da forma fonte por causa de, a locução por causa que funciona como conector de orações, apresentando, assim, um estatuto conjuncional.

A aplicação dos critérios propostos por Kortmann (1997) ao caso do por causa que atesta o seu caráter conjuncional. O autor defende que os conectores interclausais que têm como base um nome, seguido do item que, podem ter seu estatuto conjuncional garantido pelo cumprimento de pelo menos um dos critérios aqui tomados na formulação de Longhin-Tomasi:

(a) devem exibir uma fusão mínima;

(b) devem ter perdido pelo menos algumas de suas propriedades originais; e,

(c) devem ter pelo menos uma interpretação que não é totalmente recuperável a partir do significado das partes (condição de nãocomposicionalidade). (LONGHIN-THOMAZI, 2011, p. 155)

O critério (a), seguindo a interpretação seguindo a interpretação da autora, refere-se à dois aspectos: i) posição fixa dos termos que formam a locução e ii) impossibilidade de inserção de material interveniente. O primeiro aspecto se aplica sem restrições à forma por causa que, na medida em que não é possível inverter a ordem dos elementos que a compõem. Mas um dos dados encontrados impede que o mesmo seja dito em relação ao segundo aspecto, já que essa locução ainda permite a inserção de material interveniente, conforme se observa a seguir:

(2) DOC.: Por que que elas são... As duas são suas inimigas? INF.: Ah puque a primeira vez ela falô mentira pra mim eu perdi ponto no trabalho que valia dez pontos de Ciências. Por causa assim que eu num gosto, é, ela só fica fofocano de mim, mas eu num ligo. (PM, MAR, 65) ${ }^{6}$

\footnotetext{
${ }^{6} \mathrm{~A}$ identificação dos exemplos se dá da seguinte forma: a primeira sigla refere-se ao corpus; a segunda, à região ou comunidade catalogada e, por fim, apresenta-se a identificação do informante, que pode ser feita através da abreviação do seu nome ou através de algum número. Por exemplo, em "PM, MAR, 65", têm-se: Projeto Mineirês, Mariana (cidade) e informante 65.
} 
Esse caso chama a atenção por apresentar o item assim intercalado à locução por causa que, o que pode ser um indício de que ela não está totalmente gramaticalizada, diferentemente do conector causal porque. Com isso, a "fusão" referida no critério (a) acima é relativa para o caso da locução em análise.

O critério (b) diz respeito a perdas de propriedades semânticas e estruturais. A perda de propriedade semântica se manifesta, sobretudo, nos casos em que por causa que estabelece a relação de causalidade no domínio dos atos de fala, por exemplo, em que não se pode identificar a causa real entre dois eventos, o que estaria sugerido no nome causa, base da locução. Nos enunciados abaixo, as orações introduzidas pela locução não representam uma causa real dos segmentos a que se ligam, mas uma justificativa para atos de fala declarativos:

(3) Eu num fiz nada. Só o que podia fazê é que eu disse ele: ó, só num já matei tu e ela causa que eu num tenho revolve bom. (PV, S, 05)

(4) Se eu tivesse estudo eu tava aqui, batendo poêra, cortano mato, vendo a hora de... de... de... tomano topada den'de toco... ôch! Tava era na cidade procurano emprego bom. Por causa de que uma pessoa sem estudo tá na cidade ainda num arranja nem po sal, né não? (PV, S, 02)

A perda estrutural, por sua vez, parece ser mais evidente que a semântica. Em $98 \%$ dos dados, a locução por causa que apresenta algum tipo de erosão de um ou mais dos constituintes da forma fonte, observado no apagamento das preposições por ou de ou da vogal temática $a$ do nome causa, tendendo a constituir-se numa forma mais reduzida. A tabela ${ }^{7}$ a seguir exibe a hegemonia de variantes reduzidas:

\begin{tabular}{lcc}
\hline Variante & Frequência Token & $(\%)$ \\
\hline por causa de que & 02 & 02 \\
por causa que / por causo que & 87 & 87 \\
causa que / causo que / caus'que & 11 & 11 \\
\hline
\end{tabular}

Tab. 1: Frequência Token das variantes de por causa que.

\footnotetext{
${ }^{7}$ A aferição dessas frequências pauta-se na proposta de Bybee (2003). Dessa maneira, os dados são organizados como frequência token e type: a primeira diz respeito à frequência de um item independentemente de sua função; a segunda refere-se à frequência das diferentes funções que um dado item ou construção assume.
} 
A partir das considerações atinentes ao critério (b), é possível inferir que o (c) também é aplicável ao por causa que: sendo utilizada em contextos em que não há o estabelecimento da relação causal em sentido estrito, há casos em que o uso dessa locução independe do significado do nome causa, tomada em sentido estrito, que constitui uma de suas partes.

O quadro abaixo apresenta as principais propriedades do conector por causa que que asseguram o seu estatuto conjuncional. Este quadro baseia-se na proposta de Kortmann (1997) e foi apresentado em Longhin-Thomazi (2011, p. 165) no seu estudo sobre o conector (n) a hora que. Dessa forma, foi preciso implementar algumas alterações, sobretudo na segunda coluna, de modo a adequá-lo ao caso da locução por causa que.

\begin{tabular}{|c|c|}
\hline $\begin{array}{l}\text { Tendências na Gramaticaliza- } \\
\text { ção de conectores }\end{array}$ & $\begin{array}{l}\text { Fatos da gramaticalização de } \\
\text { por causa que }\end{array}$ \\
\hline $\begin{array}{l}\text { 1. perda de transparência formal } \\
\text { e semântica }\end{array}$ & $\begin{array}{l}\text { 1. formulaicidade: conector } \\
\text { perifrástico }\end{array}$ \\
\hline $\begin{array}{l}\text { 2. perda de substância foné- } \\
\text { tica/morfológica }\end{array}$ & $\begin{array}{l}\text { 2. perda das preposições } d e \text { e/ou } \\
\text { por - alteração ou perda da vogal } \\
\text { temática do nome (causa } \sim \text { causo } \\
\sim \text { caus') }\end{array}$ \\
\hline 3. perda de liberdade sintática & $\begin{array}{l}\text { 3. posição fixa no início das } \\
\text { orações }\end{array}$ \\
\hline $\begin{array}{l}\text { 4. desbotamento do conteúdo } \\
\text { lexical do item nuclear da locução }\end{array}$ & $\begin{array}{l}\text { 4. desbotamento do nome causa: } \\
\text { opacidade, em alguns casos, da } \\
\text { noção de causa estrita. }\end{array}$ \\
\hline $\begin{array}{l}\text { 5. aumento de significados } \\
\text { gramaticais, com aumento da } \\
\text { assimetria forma-significado }\end{array}$ & $\begin{array}{l}\text { 5. usos em domínios de causali- } \\
\text { dade mais abstratos (Cf. seção } \\
\text { abaixo) }\end{array}$ \\
\hline
\end{tabular}

Quadro 1: Gramaticalização e estatuto conjuncional de por causa que.

\section{Usos do conector por causa que no português falado}

Para caracterizar os padrões de uso do conector por causa que, são adotadas as propostas de Sweetser (1991) e Trougott e König (1991). Assim, esses padrões são interpretados a partir de uma análise semântico-pragmática. Todas as ocorrências encontradas estão no domínio semântico-pragmático da causalidade, mas, por ser esse um domínio amplo e fluido, é preciso estabelecer um continuum em que cada ponto representa uma noção diferente de causa. Dessa forma, foi possível determinar, com base em Sweetser (1991), três types 
para os 100 tokens de por causa que encontrados nos corpora deste trabalho. Cada type refere-se, portanto, a um dos domínios de causalidade, quais sejam, o referencial, o epistêmico e o dos atos de fala. No entanto, um dos dados parece estabelecer a relação de causalidade em um nível mais abstrato e elevado que o dos atos de fala, o que não é previsto na proposta de Sweetser (1991). Paiva (1995) e Paiva e Braga (2010) apontam ocorrências da conjunção porque nesse nível, que chamam de discursivo. Segundo as autoras, trata-se de um nível acima da sentença, responsável pela introdução de tópico ou subtópico. A ocorrência a seguir exigiu a inclusão do dominio discursivo como um dos types possíveis de por causa que:

(5) ... eu tenho um grande amigo, o NP. Né? Eu rio muito quando eu lembro dessa história. Por causa que tem uma fazenda aqui... aqui... que chama NP. Né? E numas férias aí de janeiro de 99, né? A gente pegô e saiu. Né? Saímos pra passeá. Né? Eu e mais cinco colegas, contano com o NP. Então a gente era muito inocente. Sabe? E a gente curtia muito a vida. Era muita trapalhada, era uma coisa muito legal. E uma certa hora, o NP pegô... e a gente tava brincano, chamano ele de bafo. Né? - Ô bafo! Aí... NP: - Ổ! Tem dó! Tem dó! Num fala isso aí não! E ele ta até aqui presente. Né? E a gente foi falando. Ô bafo daqui, ô bafo dali e ele muito bravo, foi se irritano, foi se irritano... quando vê.Né? Ele pega e... nós pegamo e começamo a brincá . Né? E num sei por que que *nóis chamava ele de bafo. Aí, ele muito bravo disse: - È, num sei que, a vó NP que começô a me chamá de bafo. (PM, ARC, 09)

No trecho acima, mais do que ligar duas orações, o conector por causa que introduz uma narrativa que não pode ser tomada como causa propriamente dita do segmento "Eu rio quando eu lembro dessa história". Do mesmo modo, parece não funcionar como uma justificativa para um ato de fala, já que introduz uma porção discursiva mais ampla. Dada a "frouxidão" semânticopragmática entre o segmento efeito e a narrativa introduzida pela locução por causa que, pode-se defender que a relação causal é estabelecida no domínio discursivo. O continuum que caracteriza o domínio semântico-pragmático da causalidade seria assim descrito:

\section{NÍVEL REFERENCIAL > NÍVEL EPISTÊMICO > NÍVEL DOS ATOS DE FALA > NÍVEL DISCURSIVO}

As demais ocorrências representam casos bastante prototípicos dos domínios postulados por Sweetser (1991). Em (6) e (7), por exemplo, é possível reconhecer que a relação causal se dá no domínio referencial. No primeiro caso, o fato de o tempo estar seco é causa real para a ausência de peixe no rio. $\operatorname{Em}(7)$, a morte da mãe do rapaz de quem o informante fala também representa uma causa real para o fato de ele ter sido criado por outra pessoa: 
(6) DOC.: E quando o rio enche tem muito peixe? INF.: De vez em quano dá, né. Agora não tá dano por causa que o tempo tá seco, quano o tempo tá seco assim, ele num sai, né, acho qu'eles se esconde. (ALFSB, RC, 02)

(7) Ele... minha mãe tomô ele causa que a mãe dele morreu, tomô pequenininho que era tudo parente, aí tomô e criô ele, aí depois que juntô tudo, começõ a namorá. Aqui tem muita gente casada com primo. (PV, S, 05)

Nos exemplos (8) e (9) a seguir, uma crença ou conclusão do falante condiciona o estabelecimento da relação causal, localizando-a no domínio epistêmico. Em (8), é possível inferir a seguinte relação: "sou um cara inteligente, logo há muitas meninas que querem me namorar". No exemplo seguinte, o falante aponta como causa de a seleção brasileira de futebol tornarse hexacampeã a sua crença de que ela irá até a final, sendo, por conseguinte, vencedora:

(8) As menina daqui sempre gosta de mim, entendeu? Tudo, um monte de menina aí é tudo louca pa namorar comigo por causa que eu sou um cara inteligente, entendeu? (ALFSB, J, 08)

(9) ...e aí chegou dois mil e dois Brasil vem-ceu e agora esse ano ele vai se tornar hexacampeão e [q] por causa que vai terminar na final + Brasil vez Alemanha (PM, BH, 07)

Em ambos os casos acima, a relação causal não se estabelece com base em eventos do mundo extralinguístico; sendo, portanto, epistêmica, isto é, uma relação que se pauta por um conhecimento, julgamento ou crença do falante. Pode-se dizer, ainda, que em (8) e (9) há subjetivização da expressão da causalidade, na medida em que é possível observar nesse enunciado a presença de certo nível de envolvimento do falante: "epistemic relations [...] involve beliefs of a concluding protagonist with whom the speaker must share a number of assumptions in order to understand the causal relation" (Degand; Pander maat, 2003: 177) ${ }^{8}$.

Nos dois casos a seguir, a compreensão da relação de causalidade exige um distanciamento ainda maior do mundo referencial:

\footnotetext{
${ }^{8}$ Relações epistêmicas trazem crenças de um protagonista que tem a palavra final: com ele o falante deve partilhar uma série de suposições para entender a relação causal. (Tradução do autor do presente trabalho)
} 
(10) Ô, menino! Ô... ô, Domingo abre... abre essa portêra aqui, pa mim, fazendo favô! Por causa que eu tô convesano com rapa'í... (PV, H, 06)

(11) Eu falei com minha vó assim ô vó cê num pode falá assim não por causa qui qualquer coisa se a cobra qui na é a égua não acerta na cobra, a cobra pode enrolá no pé da égua matá o animal e ainda a pessoa que tá em cima num é? (PM, MAR, 61)

As orações causais em (10) e (11) não codificam uma causa que seja responsável pela ocorrência de um evento ou estabelecimento de um estado de coisas. Na realidade, apresenta-se, através da oração causal, uma justificativa para o ato de fala realizado no segmento efeito. Assim, em (10), é feito um pedido e, para que sejam maiores as chances de ele ser atendido, o falante o justifica: "peço Y porque X". Em (11), o segmento efeito codifica um ato de fala, que se apresenta como um conselho. A oração que segue esse ato de fala é, portanto, uma justificação : "aconselho Y porque X". A tabela seguinte apresenta os resultados da análise acima descrita:

\begin{tabular}{c|cccc}
\hline Frequência & \multicolumn{4}{|c}{ Frequência Type: domínios de causalidade } \\
\cline { 2 - 5 } Token & Referencial & Epistêmico & Atos de Fala & Discursivo \\
100 & 81 & 5 & 13 & 1 \\
$100 \%$ & $81 \%$ & $5 \%$ & $13 \%$ & $1 \%$ \\
\hline
\end{tabular}

Tab. 2: Frequência Type de por causa que.

Como se pode ver, mais da metade das ocorrências de por causa que se concentra no domínio referencial. Uma explicação possível pode ser encontrada na proposta de Traugott e König (1991). Segundo eles, à medida que se tornam mais gramaticalizadas, as formas não sofrem exatamente um desbotamento semântico (Cf. Gonçalves et al., 2007: 36), mas um aumento de informatividade, pautado pela expressão subjetiva do falante. Após revisitarem a proposta de Traugott (1982 apud Traugott; König, 1991: 189), que prevê uma trajetória de mudança semântica para um item em gramaticalização (proposicional $>$ [textual] $>$ expressivo), Traugott e König postulam três tendências semântico-pragmáticas presentes no processo de gramaticalização:

Tendência I: significados baseados em descrições de situações exteriores > Tendência II: significados baseados em situações textuais (coesivas) > Tendência III: significados tendem a se tornar cada vez mais baseados em atitudes e crenças subjetivas dos falantes com relação à determinada situação.

Os usos de por causa que se concentram, portanto, na primeira tendência, visto que a maioria de suas ocorrências estabelece a relação de causalidade 
em um nível que se relaciona diretamente a situações exteriores (domínio referencial). Vale ressaltar, entretanto, que a tendência textual parece se sobrepor às demais, pois, além de explicitar a relação de causalidade, o conector por causa que, na grande maioria dos casos, introduz uma informação nova ao segmento anterior, sendo responsável, assim, pela continuidade tópica (Cf. seção 4 abaixo). A última tendência, conforme se verifica na tabela acima, não se manifesta em grande escala nos dados analisados. Conforme Traugott e König (1991, p. 192), o desenvolvimento de valores mais pragmáticos de uma forma em gramaticalização (tendência III) acontece em estágios mais avançados. Dessa forma, o fato de o conector por causa que ser utilizado com maior frequência no domínio referencial estaria de acordo com essa hipótese, já que, conforme apontam Amorim (2011) e Paiva (2001), essa locução encontra-se num estágio incipiente de gramaticalização.

\section{Ordenação e estatuto informacional das cláusulas por causa que}

A ordem e o estatuto informacional dos enunciados causais em português se apresentam como aspectos já bastante discutidos por diferentes autores (Cf. Paiva, 1991; 1999; Lopes, 2004; Neves, 1999; 2000). Entretanto, apenas Neves (2000) considera enunciados causais com por causa que.

A análise dos dados mostra que as orações ou porções discursivas introduzidas por por causa que podem se posicionar antes ou depois do segmento efeito. Em alguns casos, entretanto, há certa ambiguidade, de modo que não se pode precisar se o segmento causal está diretamente relacionado ao segmento anterior ou posterior. Esses casos ambíguos também são identificados por Paiva $(1995 ; 1999)$, em estudos sobre os usos de porque no discurso oral. Os exemplos seguintes mostram, respectivamente, a posposição, anteposição e a ambiguidade posicional das cláusulas por causa que:

(12) Agora tem muito pessoal, assim, da. . da região, aí, muita vez vota em Helvécia por causa que tem uma assistência melhó. Sabe que o prefeto também de Caravela num vale nada! No município nosso aí. (PV, H, 06)

(13) É, se não fosse ela, moça, já tinha rinchado de fome. Que não me confiava nada fiado não moça. Vendia nada a eu fiado não. Agora por causa qu'eu tenho minha posentadoria, eles me vende qualquer coisinha fiado, eles me vende, chega a me chamar assim na rua óh, pra comprar as coisa fiado. (ALFSB, RC, 03) 
(14) E a gente brincou das milhões das espiãs demais, por causa que tinha um montão de menina lá querendo brincar, a gente falô assim, as dez espiãs demais! (PM, MAR, 49)

É preciso destacar que a ocorrência apresentada em (13) refuta o que afirma Neves (2000, p. 809): “Apenas iniciam orações causais pospostas as conjunções pois, que, pois que, tanto mais que, por causa que, por isso que" (grifos acrescidos). Ainda que em pouca quantidade (6\%), a análise aqui realizada atesta que é possível a ocorrência do conector por causa que em início de orações causais antepostas.

No exemplo (14), não se pode determinar com precisão a que segmento a cláusula por causa que se refere. Ter-se-iam as seguintes possibilidades:

(14a) E a gente brincou das milhões das espiãs demais, por causa que tinha um montão de menina lá querendo brincar.

(14b) Por causa que tinha um montão de menina lá querendo brincar, a gente falô assim, [vamos brincar de] "as dez espiãs demais"!

A tabela a seguir apresenta os resultados em relação à ordenação das cláusulas por causa que:

\begin{tabular}{|c|c|c|}
\hline Ordem das Cláusulas por causa que & Frequência & $(\%)$ \\
\hline Anteposição & 06 & 06 \\
\hline Posposição & 90 & 91 \\
\hline Anteposição/Posposição & 03 & 03 \\
\hline Total $^{9}$ & 99 & 100 \\
\hline
\end{tabular}

Tab. 3: Ordenação de cláusulas por causa que.

Como se visualiza acima, a ordem não marcada das cláusulas por causa que é a posposição (91\%). Nesse aspecto, o conector por causa que se comporta como a conjunção prototípica porque, conforme mostram Paiva e Braga (2006).

Outro aspecto importante relacionado ao comportamento das cláusulas causais em geral diz respeito ao seu estatuto informacional. Dessa maneira, seguindo a taxonomia apresentada por Prince (1981, apud Pezatti, 2004: 182), a informação codificada pelas cláusulas causais por causa que foi classificada em nova, velha e inferível. O estudo da relação entre o estatuto informacional

\footnotetext{
${ }^{9}$ Desta análise, foi excluído o caso em que o conector apresentou um comportamento mais discursivo, dada a acentuada frouxidão sintático-discursiva existente entre o segmento efeito e o causal.
} 
dos constituintes e a codificação gramatical tem apresentado resultados que corroboram a premissa de que a forma linguística não está isenta de variáveis cognitivo-discursivas. Com base nisso, o estatuto informacional das orações causais introduzidas pela locução por causa que foi investigado com o intuito de testar a hipótese segundo a qual sua ordenação teria a ver com o tipo de informação por ela veiculada, como mostra Paiva (1991) a respeito das orações causais introduzidas pelo conector "porque":

A ordenação das cláusulas na organização dos enunciados é restrita também pela estrutura de informação do texto. A codificação de informação no discurso se faz, em geral, de acordo com um princípio de que a informação já compartilhada pelos interlocutores precede a informação nova, não compartilhada. Assim como continuidade tópica, esse princípio explica diversos fenômenos linguísticos, apontando a indissociabilidade entre sintaxe e discurso. A transposição deste princípio para a organização dos enunciados prediz que cláusulas [causais] com informação nova serão mais propensas à posposição, enquanto cláusulas com informação velha serão propensas à anteposição. (Paiva, 1991: 74)

A tabela seguinte apresenta os resultados do estatuto informacional das cláusulas por causa que encontradas nos corpora desta pesquisa:

\begin{tabular}{ccc}
\hline Tipo de informação & Frequência & $\mathbf{( \% )}$ \\
\hline Nova & 85 & 92 \\
Velha & 09 & 06 \\
Inferível & 02 & 02 \\
Total $^{10}$ & 96 & 100 \\
\hline
\end{tabular}

Tab. 4: Estatuto informacional das cláusulas por causa que.

No que tange ao estatuto informacional, esses resultados demonstram que as cláusulas por causa que apresentam comportamento idêntico ao que se observa nas cláusulas introduzidas por porque: ambas são pontos de introdução de informação nova.

A fim de verificar a hipótese de Paiva (1991), acima assinalada, foram cruzados os resultados referentes à ordem e ao estatuto informacional:

\footnotetext{
${ }^{10}$ Foram excluídos desta análise os 03 casos em que não se pôde precisar a ordem da cláusula causal e o caso cujo uso foi aqui interpretado como discursivo.
} 


\begin{tabular}{ccccc}
\hline \multirow{2}{*}{ Estatuto Informacional } & \multicolumn{4}{c}{ Ordem } \\
& Anteposição & (\%) & Posposição & $\mathbf{( \% )}$ \\
\hline Nova & 2 & 33 & 83 & 93 \\
Velha & 3 & 50 & 5 & 5 \\
Inferível & 1 & 17 & 2 & 2 \\
Total & $\mathbf{6}$ & $\mathbf{1 0 0}$ & $\mathbf{9 0}$ & $\mathbf{1 0 0}$ \\
\hline
\end{tabular}

Tab. 5: Cruzamento das propriedades ordenação e estatuto informacional das cláusulas por causa que

Dada a diferença tênue entre informação velha e informação inferível, podese afirmar que quatro dos seis casos de cláusulas por causa que antepostas, isto é, $67 \%$, codificam informação já mencionada anteriormente, o que aproxima essas cláusulas às demais orações introduzidas por outros conectores causais. Assim, os resultados apresentados em relação às cláusulas por causa que mantêm válida a afirmação de que

As cláusulas causais são preferencialmente pospostas quando codificam uma informação que ainda não foi mencionada no contexto discursivo. Tendem, ao contrário, a ser antepostas, quando codificam informação que já ocorreu no discurso anterior ao enunciado causal. (Paiva, 1991: 86).

Esses resultados também parecem legitimar o que afirma Lopes (2004), que explicita o papel discursivo da ordenação dos enunciados causais:

Quando a oração causal integrada antecede a oração principal, o estado de coisas por ela denotado constitui informação pressuposta ou acessível ao alocutário e o locutor manifesta a sua atitude, assumindo-a como verdadeira, desajustada, inadequada... Quando a oração causal integrada ocorre depois da principal, o estado de coisas denotado na oração causal é apresentado como informação nova e o locutor é neutro quanto à verdade ou adequação da asserção. Deste modo a posição inicial da oração causal integrada é sempre uma posição mais marcada do que a posição final. (Lopes, 2004: 108)

Para ilustrar a ideia acima, veja-se novamente o exemplo (13), agora retomado como (15) e inserido numa porção discursiva mais ampla: 
O conector por causa que: gramaticalização e...

The connective por causa que: grammaticalization and...

(15) INF: É, agora, moça, eu fui no Ri de Conta ontem paguei e cheguei aqui sem um tostão. Paguei tudo, tudo, tudo qu'eu tava deveno.

DOC: Foi?

Inf: Tirei cento e trinta só.

DOC: E chegou assim sem um tostão. Então.

INF: Paguei moça, tava deveno demais moça. Paga dez o... o outo, paga vinte o outo, cinquenta o outo, vinte o outo, até o dinheiro cabou. Cabou moça, mas dano graças a Deus, Deus me deu essa esmola. Não fosse essa esmola ninguém me vendia fiado não.

DOC: Graças a Deus que a senhora tem a sua aposentadoria.

INF: É, se não fosse ela, moça, já tinha rinchado de fome. Que não me confiava nada fiado não moça. Vendia nada a eu fiado não. Agora por causa qu'eu tenho minha posentadoria, eles me vende qualquer coisinha fiado, eles me vende, chega a me chamar assim na rua óh, pra comprar as coisa fiado. (ALFSB, RC, 03)

Toda a fala apresentada se desenvolve a partir de um tópico: o recebimento da aposentadoria da informante. Esse dinheiro, ainda que pouco ("essa esmola"), é apresentado como o grande responsável pela manutenção de sua vida financeira, garantindo-lhe, inclusive, ter crédito nos estabelecimentos da localidade onde vive. A cláusula causal em destaque representa, portanto, uma informação velha, ou seja, recorrentemente mencionada em pontos anteriores do discurso em que se insere, o que lhe dá o caráter de pressuposta para o alocutário, permitindo que seja apresentada pelo locutor como verdadeira, como assinala Lopes (2004: 108).

Assim como os demais conectores causais (Cf. Paiva, 1991; 1999; Neves, 1999; 2000), observa-se, portanto, que a locução por causa que tende a introduzir orações que se pospõem ao segmento efeito e que, em sua maioria, trazem uma informação nova. Dessa forma, as cláusulas por causa que, no português falado, são não-icônicas, uma vez que não refletem a ordem dos acontecimentos no mundo: CAUSA-EFEITO. No entanto, Neves (2000, p. 816) destaca que não é adequado esperar que a ordenação de enunciados reflita a pura disposição cronológica de eventos, uma vez que cada estruturação discursiva pode, em primeira instância, caracterizar-se como uma versão particular da apresentação dos fatos, resultante da percepção (perspectiva cognitiva) do falante. Nesse sentido, "a ordenação consequência-causa num enunciado pode ser considerada icônica no sentido de que reflete a ordem pela qual, de um efeito, se deduz a causa" (Neves, 2000, p. 816).

Embora a ordenação CAUSA-EFEITO possa ser considerada prototipicamente icônica, o fato é que, nas construções com conectores causais, a sua 
incidência é bastante baixa (Cf. Paiva, 1991; 1999). Conforme se viu acima, apenas $6 \%$ das cláusulas por causa que encontradas nos corpora aparecem antepostas. Muitas são as explicações para essa baixa incidência. Uma delas está relacionada ao nível de monitoramento linguístico. Assim, Chafe (1988 apud Paiva, 1999) defende que a baixa frequência de cláusulas causais antepostas no discurso oral se deve ao reduzido nível de elaboração linguística que, geralmente, caracteriza essa modalidade. Paiva (1999: 265), analisando a questão da ordem das cláusulas porque em diferentes corpora, mostra que a maior incidência da anteposição da oração causal se dá em situações de elocução formal. Nesse sentido, a hipótese de Chafe pode ser apontada como explicação possível para a baixa ocorrência de cláusulas por causa que antepostas, já que todos os corpora consultados para este trabalho representam amostras de fala obtidas a partir de entrevistas que procuraram manter um contexto distenso entre documentador e informantes. É possível dizer, ainda, que "a existência de uma estrutura alternativa - X então $Y$ - para a anteposição da causa contribui para reduzir a frequência de porque X, Y [por causa que X, Y]" (Paiva, 1991: 171).

\section{Correlações modo-temporais nas construções com por causa que}

No que tange à relação modo-temporal nas construções causais com por causa que, observa-se uma variedade de combinações quanto ao tempo do verbo do segmento efeito e ao do segmento causal. No que diz respeito ao modo, tal variedade não se manifesta na mesma proporção, visto que, na grande maioria dos casos, o uso do indicativo predomina, sobretudo no segmento causal, em que não se registrou a presença de outro modo. A alta frequência do indicativo nas cláusulas por causa que corrobora o fato de que, ainda que seja estabelecida com base em conclusões/crenças do falante, tendo, assim, um valor epistêmico, a relação causal é sempre apresentada com um certo grau de certeza, conforme afirma Neves (2000: 818): "O indicativo é o modo voltado para expressar causa, já que a expressão de causa constitui uma proposição com certo grau de certeza" (grifo da autora). As correlações modo-temporais identificadas nas construções em análise estão registradas na tabela abaixo ${ }^{11}$ :

\footnotetext{
${ }^{11} \mathrm{~A}$ diferença no número total de ocorrências em relação às tabelas anteriores deve-se ao fato de que, nesse grupo de fatores, foram desconsideradas as construções causais sem uma estruturação prototípica mínima, como os casos em que a oração causal não se relaciona a um segmento efeito explícito.
} 
O conector por causa que: gramaticalização e...

The connective por causa que: grammaticalization and...

\begin{tabular}{llcc}
\hline Segmento Efeito & Segmento Causal & Total & $\mathbf{( \% )}$ \\
\hline \multirow{4}{*}{ Presente do Indicativo } & Presente do Indicativo & 32 & 49 \\
& Pret. Perfeito do Ind. & 3 & 5 \\
& Pret. Imp. do Ind. & 1 & 1 \\
& Fut. do Pres. do Ind. & 2 & 3 \\
\hline \multirow{2}{*}{ Pretérito Perfeito do Indicativo } & Presente do Indicativo & 4 & 6 \\
& Pret. Perfeito do Ind. & 6 & 9 \\
& Pret. Imp. do Ind. & 4 & 6 \\
\hline \multirow{2}{*}{ Pretérito Imperfeito do Indicativo } & Pret. Perfeito do Ind. & 1 & 1 \\
& Pret. Imp. do Ind. & 5 & 8 \\
\hline \multirow{2}{*}{ Futuro do Presente do Indicativo } & Presente do Indicativo & 2 & 3 \\
& Pret. Perfeito do Ind. & 1 & 1 \\
& Fut. do Pres. do Ind. & 1 & 1 \\
\hline Fut. do Pretérito do Ind. & Pret. Imp. do Ind. & 2 & 3 \\
\hline Imperativo & Presente do Indicativo & 1 & 1 \\
\hline Total & & $\mathbf{6 5}$ & $\mathbf{1 0 0}$ \\
\hline
\end{tabular}

Tab. 6: Correlações modo-temporais em construções com por causa que.

Conforme mostram os números acima, a maioria das construções causais com por causa que apresenta verbo no presente do indicativo tanto no segmento efeito quanto no segmento causal (49\%). Em seguida, têm-se as combinações presente/futuro, pretérito perfeito/pretérito perfeito e pretérito imperfeito/pretérito imperfeito como os mais frequentes. A combinação presente/presente (indicativo) também é frequente nas construções com porque (Cf. Neves 1999; 2000; Paiva, 1991). A correlação modo-temporal representa, portanto, mais uma propriedade gramatical em comum entre as cláusulas porque e as que são introduzidas pela locução por causa que.

Os exemplos ${ }^{13}$ a seguir ilustram algumas das correlações apontadas na tabela acima:

(16) Dia de hoje tá melhor por causa que hoje tem... tem estrada pra tudo quanto é canto. (ALFSB, RC, 04) - Presente/Presente

(17) Os transporte agora tá bom, sabe? Por causo que colocou essas perua agora com esse sistema aí. (ALFSB, FS, 07) - Presente/Pret. Perfeito

\footnotetext{
${ }^{12}$ Todas as formas encontradas para esse tempo são perifrásticas.

${ }^{13}$ Alguns exemplos supracitados serão retomados sob diferente indicação numérica.
} 
(18) E o computador da minha mãe é novo, por causa que o dela estava dando pala [defeito]. (PM, MAR, 49) - Presente/Pret. Imperfeito

(19) Aí ela não podi fica de castigo, por causa que num vai dar pra ela fazê o campeonato. (PM, MAR, 49) - Presente/Fut. do Presente

(20) Ô, menino! Ô...ô, Domingo abre... abre essa portêra aqui, pa mim, fazendo favô! Por causa que eu tô convesano com rapa'í... (PV, H, 06) - Imperativo/Presente

\section{Considerações Finais}

Através de uma investigação sincrônica, este trabalho pôde apresentar uma descrição de propriedades gramaticais e semântico-pragmáticas da locução por causa que, além de atestar o seu estatuto conjuncional. Foi possível, ainda, apresentar indícios diacrônicos do seu processo de gramaticalização, aventando hipóteses sobre a sua emergência.

As análises evidenciaram que, em muitos aspectos, essa locução aproximase do conector porque. Assim, conforme assinalado no decorrer do trabalho, as cláusulas por causa que caracterizam-se por: a) terem a posposição (em relação à cláusula efeito) como a ordem não marcada; b) codificarem informação nova, na grande maioria dos casos; c) tenderem a antepor-se ao segmento efeito, quando codificam informação velha; d) aparecerem em construções em que há a correlação verbal presente do indicativo/presente do indicativo e e) marcarem a relação de causalidade, mormente, no domínio referencial. Com exceção da propriedade e), todas as outras são identificadas nas cláusulas introduzidas pelo conector porque, como mostram Paiva (1991), Neves (1999; 2000), para citar alguns.

\section{Referências}

AMORIM, Fabrício da Silva. 2011. Alguns indícios sincrônicos da gramaticalização do conector por causa (de) que. Domínios de Linguagem, vol $5, \mathrm{n}^{\mathrm{o}} 1$.

BARRETO, Therezinha. 1999. Gramaticalização das conjunções na história do português. Tese de Doutorado. UFBA, Salvador, BA.

BYBEE, J. 2003. Mechanisms of change in grammaticalization: the role of frequency. In: JOSEPH, B., JANDA, R. The Handbook of Historical Linguistics. Oxford: Blackwell. 
DEGAND, Liesbeth; PANDER MAAT, Henk. 2003. A contrastive study of Dutch and French causal connectives on the Speaker Involvement Scale. A. Verhagen; J. van de Weijer (eds.) Usage based approaches to Dutch. Utrecht: LOT, 175-199.

GONÇALVES, Sebastião Carlos Leite; LIMA-HERNANDES, Maria Célia.; CASSEB-GALVÃO, Vânia Cristina (org.). 2007. Introdução à Gramaticalização: em homenagem a Maria Luiza Braga. São Paulo: Parábola Editorial. HOPPER, Paul; TRAUGOTT, Elizabeth. Grammaticalization. 1993. Cambridge: Cambridge University Press.

LONGHIN-THOMAZI, Sanderléia Roberta. Flutuação e gramaticalização no paradigma dos juntores em português forma, significado e história de (na) hora que. Filologia e Linguística Portuguesa, São Paulo, v. 13, n. 1, p. 147-166, jun. 2011. ISSN 2176-9419. Disponível em: $<$ http://www.revistas.usp.br/flp/article/view/59882>. Acesso em: 13 set. 2013. doi:http://dx.doi.org/10.11606/issn.2176-9419.v13i1p147-166.

LOPES, Maria Helena C. Couto. 2004. Aspectos sintácticos, semânticos e pragmáticos das construções causais: contributo para uma reflexão sobre o ensino da gramática. Portugal: Faculdade de Letras da Universidade do Porto. Tese de Doutorado,.

NEVES, Maria Helena de Moura. 2000. Gramática de usos do português. São Paulo: Unesp, p. 801-829.

NEVES, Maria Helena de Moura. 1999. As construções causais. In: NEVES, M. H. M. (org.). Gramática do português falado, vol. VII: Novos estudos. São Paulo: Humanitas, p. 461 - 496.

PAIVA, Maria da Conceição. 2001. Gramaticalização de conectores no português do Brasil. SCRIPTA, Belo Horizonte, v. 5, n. 9,. p.35-46.

PAIVA, Maria da Conceição. 1999. A ordem não marcada das cláusulas "porque". Série Encontros Descrição do Português :Abordagens Funcionalistas, UNESP, Araraquara, v. 1, p. 263-280

PAIVA, Maria da Conceição. 1995. Empregos de porque no discurso oral. DELTA. Documentação de Estudos em Linguística Teórica e Aplicada, São Paulo, v. 11, n. 1, p. 27-39

PAIVA, Maria da Conceição. 1991. Ordenação de cláusulas causais: forma e função. Rio de Janeiro: UFRJ. Tese de Doutorado.

PAIVA, Maria da Conceição; BRAGA, Maria Luiza. 2010. Cláusulas causais introduzidas por porque: da sintaxe ao discurso. In: MOLLICA, Maria Cecília. (Org.). Usos da linguagem e sua relação com a mente humana. Rio de Janeiro: Editora Tempo Brasileiro, v. 1, p. 55-71. 
PAIVA, Maria da Conceição. 2006. Conjunções lexicais e gramaticais: o caso de por causa de. Gragoatá (UFF), v. 21, p. 73-86.

PEZATTI, Erotilde Goreti. O funcionalismo em linguística. 2004. In: MUSSALIM, Fernanda; BENTES, Anna Christina (orgs.). Introdução à linguística: fundamentos epistemológicos. São Paulo: Cortez, p. 165-216.

SWEETSER, Eve. 1991. From etymology to pragmatics. Cambridge: Cambridge University, p. 23-48.

TEIXEIRA, Jerônimo; MACEDO, Daniela. Nós fala mal, mas você pode fazer melhor. Veja, ed. 2177, ano 43, n. 32, Editora Abril: São Paulo, SP, p. 94-101, ago. 2010.

TRAUGOTT, E. C.; KÖNIG, E. 1991. The semantic-pragmatics of grammaticalization revisited. In: TRAUGOTT, E., HEINE, B. (Org.). Approaches to grammaticalization: focus on theoretical and methodological issues. Amsterdam: John Benjamins, v. 1, p. 189-218.

Recebido em: 12/04/2012

Aceito em: 23/07/2012 